Miami Nature Biotechnology Short Reports

TheScientificWorld (2001) 1 (S3), 98SR

ISSN 1532-2246; DOI 10.1100/tsw.2001.198

\title{
REQUIREMENT OF ECM AND INSULIN FOR MAINTENANCE OF LIVER-SPECIFIC FUNCTIONS AND CELL SURVIVAL IN PRIMARY RAT HEPATOCYTES
}

\author{
Jaspreet S. Sidhu, Fei Liu, and Curtis J. Omiecinski*
}

Dept. of Environmental Health, University of Washington, Box 354695, Seattle, WA 98195, USA

*cjo@u.washington.edu

INTRODUCTION. Primary rat hepatocytes are a potentially valuable model system for assessing liver-specific responses to pharmaceutical and toxicological agents. However, many culture renditions exist that are of questionable relevance to hepatocyte biology in vivo. Maintenance of liver-specific gene expression indices and patterning of appropriate hepatocyte responsiveness to drug or chemical exposure requires a highly defined and phenotypically stable culture system (1,2,3). In our laboratory's ongoing efforts to better define in vitro conditions that accurately reproduce in vivo patterns of hepatocyte expression, we have investigated the interplay between the extracellular matrix (ECM) and various trophic factors $(4,5)$. In the present study, we assessed the critical interactions of ECM and insulin in primary rat hepatocytes cultures (6) and evaluated their combined cytoprotective effects. We examined a full range of insulin concentrations, representing fasted, fed, and super-physiological levels of the hormone.

METHOD. Primary hepatocytes were isolated from adult rat liver and cultured as previously described $(3,6)$. Briefly, cells were plated on tissue culture treated or on collagen 1,4 or laminin-coated dishes. A range of dilute concentrations $(25-250 \mu \mathrm{g} / \mathrm{ml})$ of ECM was added as an overlay, $4 \mathrm{~h}$ after plating. Cells were also cultured in the presence of varying concentrations of insulin $(0,0.01,0.1,1,10,1000 \mathrm{nM})$ for a $96 \mathrm{~h}$ period. Cells were treated daily with phenobarbital (0.5 mM; PB) for $24 \mathrm{~h}$ and total RNA isolated and examined by slot-blot hybridization for cytochrome P450 (CYP) and other markers of liver-specific gene expression. In addition, cell lysates were prepared daily and examined for phosphorylation status of PKB and SAPK/JNK. Accompanying nuclear extracts were prepared for each treatment and examined by EMSA for nuclear mobilization of various transcription factors involved in hepatocyte differentiation, survival and stress response.

RESULTS. Dilute ECM additions, even 25-75 $\mu \mathrm{g} / \mathrm{ml}$, enabled preservation of normal hepatocyte morphology and markedly facilitated the response profiles of liver specific genes. Cultivation of primary hepatocytes under low concentrations of insulin $(<1 \mathrm{nM})$ resulted in the maintenance of maximal PB-inducible CYP2B1/2 and 3A1 gene expression for 48-72h postplating; although $10 \mathrm{nM}$ insulin was required to maintained appropriate induction responses at longer culture intervals. Maintenance of cultures in $<1 \mathrm{nM}$ insulin for long culture periods also resulted in compromised morphological integrity of the hepatocytes. The $1 \mathrm{nM}$ insulin concentrations were optimally effective in maintaining CYP2E1 expression up to 96h in culture at levels equivalent to that obtained in freshly isolated hepatocytes. In contrast, levels of the liver-specific genes, albumin and transferrin, were significantly reduced under the restricted insulin concentrations. A pronounced elevation in SAPK/JNK phosphorylation status 
was observed in primary hepatocytes maintained chronically in the absence of insulin. This activity increased substantially in a time-dependent manner in cells cultured in the absence of ECM overlay and was further associated with a pronounced increase in the recruitment of the AP-1 transcriptional complex. Optimal insulin $(10 \mathrm{nM})$ and ECM $(25-75 \mu \mathrm{g} / \mathrm{ml})$ concentrations were required to maintain the nuclear profile of various liver-specific transcription factors essential for cell differentiation and survival.
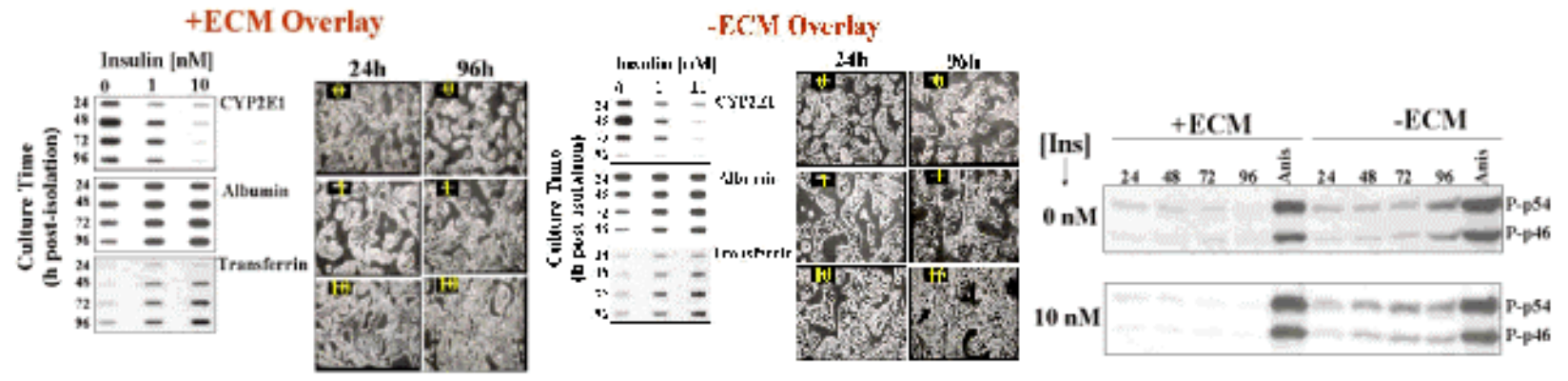

DISCUSSION. This study demonstrates the requirement for a highly defined cell culture environment, with defined additions of insulin and ECM, for examining liver-specific responses to xenobiotics, such as $\mathrm{PB}$, as well as for the maintenance of the morphological integrity of hepatocytes. An environment, therefore, favoring both differentiation and survival is proposed. These conditions should better enable accurate prediction of physiologically relevant mechanisms of drug action in culture systems relative to the response in vivo.

ACKNOWLEDGEMENT. This study was supported by the National Institute of General Medical Sciences (GM-32881) and Burroughs Wellcome Fund

\section{REFERENCES.}

1. $\quad$ Enat, R., Jefferson, D.M., Ruis-Opazo, N., Gatmaitan, Z., Leinwand, L.A., and Reid, L.M. (1984) Proc. Natl. Acad. Sci. U S A 81, 1411-1415

2. $\quad$ Schuetz, E.G., Li, D., Omiecinski, C.J., Muller-Eberhard, U., Kleinman, H.K., Elswick, B., and Guzelian, P.S. (1988) J. Cell Physiol. 134, 309-323

3. Sidhu, J.S., Farin, F.M., and Omiecinski, C.J. (1993) Arch. Biochem. Biophys. 301, 103113

4. Zaret, K.S. (1992) Hepatology 15, 1204-1205

5. $\quad$ Rana, B., Mischoulon, D., Xie, Y., Bucher, N.L., and Farmer, S.R. (1994) Mol. Cell. Biol. 14, 5858-5869

6. Sidhu, J.S. and Omiecinski, C.J. (1999) J. Biochem. Mol. Toxicol. 13, 1-9 


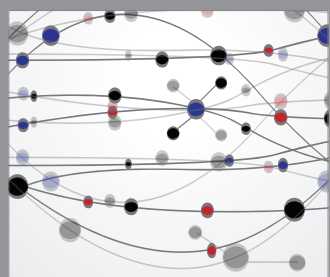

The Scientific World Journal
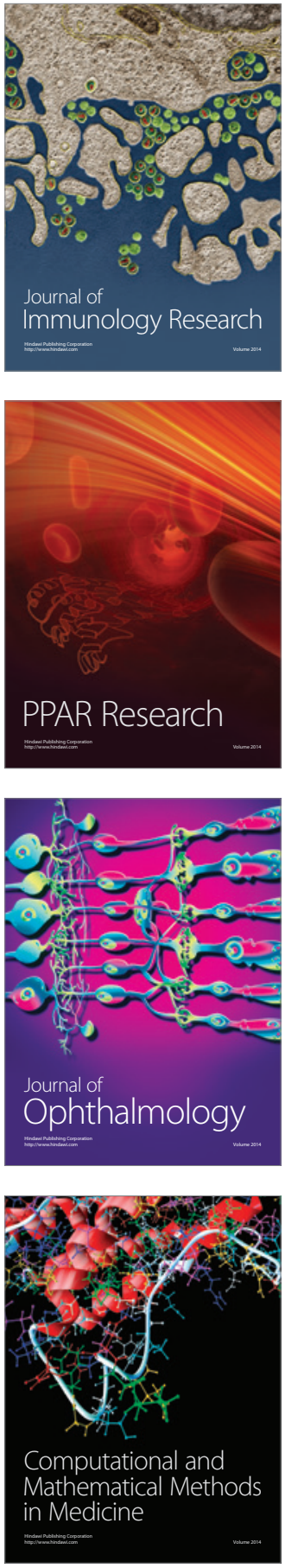

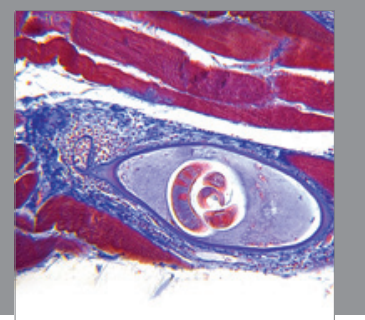

Gastroenterology

Research and Practice
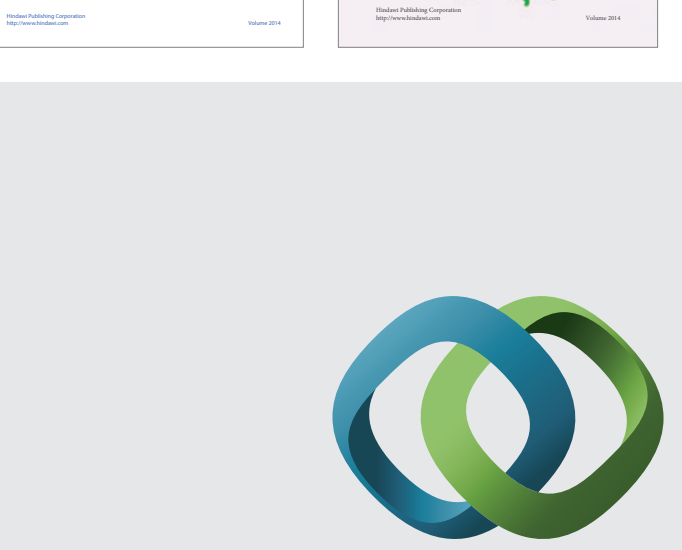

\section{Hindawi}

Submit your manuscripts at

http://www.hindawi.com
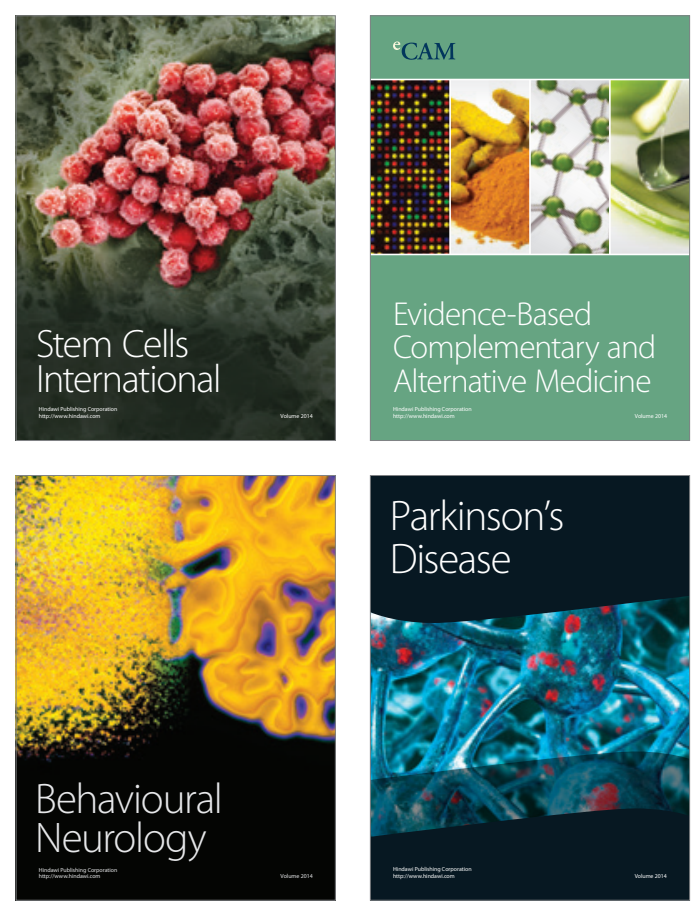

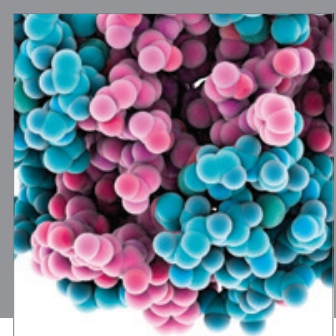

Journal of
Diabetes Research

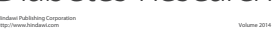

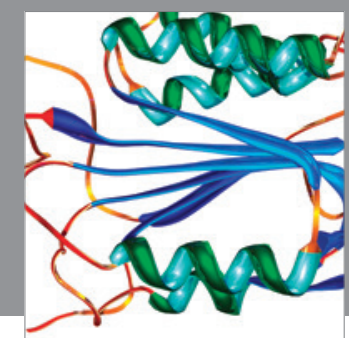

Disease Markers
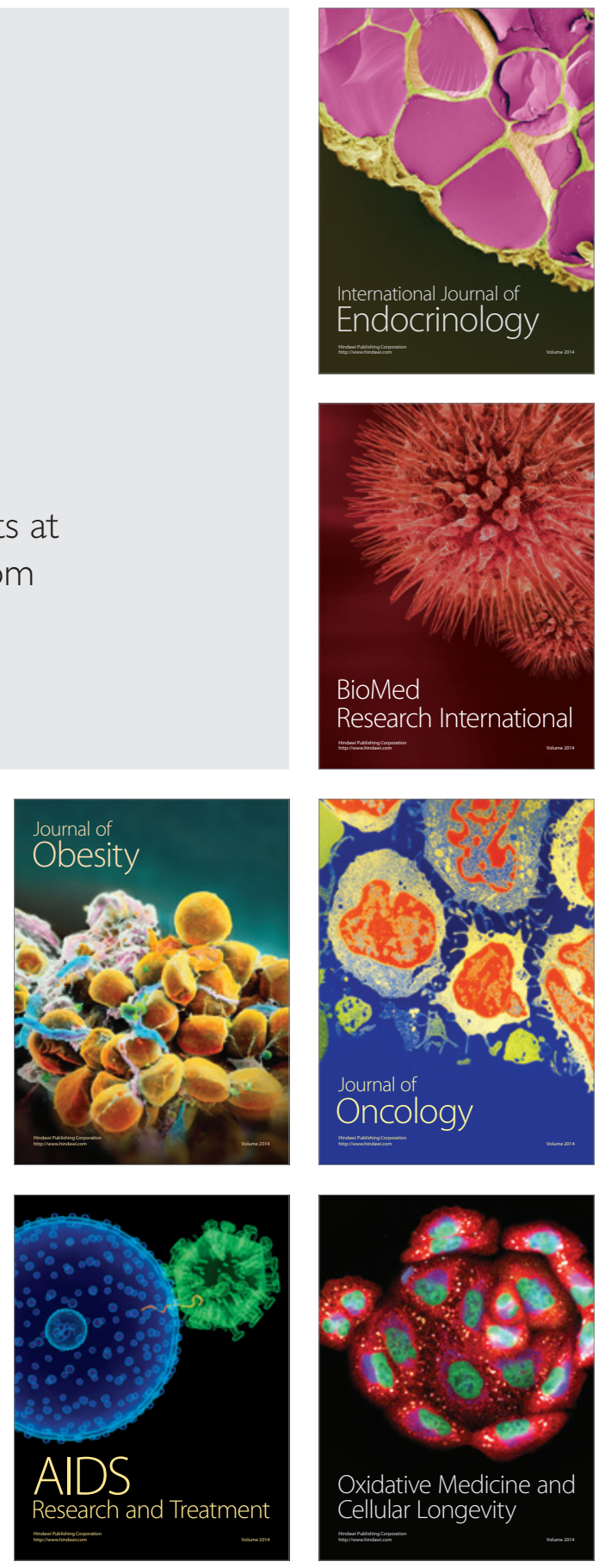